\title{
A CASE OF GIANT INGUINO- SCROTAL HERNIA
}

Dr. Neel B. Patel ${ }^{*}$

Dr. Hitendra K. Desai

Dr. Purvesh V. Doshi Dr. Bansil V. Javia $3^{\text {rd }}$ Year Resident, Department of General Surgery, B.J. Medical College and Civil Hospital, Ahmedabad, Gujarat, India. *Corresponding Author

Associate Professor, Department of General Surgery, B.J. Medical College and Civil Hospital, Ahmedabad, Gujarat, India.

$3^{\text {rd }}$ Year Resident, Department of General Surgery, B.J. Medical College and Civil Hospital, Ahmedabad, Gujarat, India.

$3^{\text {rd }}$ Year Resident, Department of General Surgery, B.J. Medical College and Civil Hospital, Ahmedabad, Gujarat, India.

\section{KEYWORDS :}

\section{INTRODUCTION}

- An inguinal hernia is a protrusion of the contents of the abdominal cavity or peritoneal fat through a defect in the inguinal area.

- The hernia sac contents are at risk of incarceration, which may lead to more serious sequelae such as bowel obstruction, and or a circulatory strangulation of the hernia contents, leading to necrosis and possible perforation of the intestine. The chance of incarceration is relatively low, between $0.3-3 \%$ per year .

- Gaint Inguinal Hernia Is More Unusual (approx 0.5\% Of Inguinal Hernias) And Significantly Challenging In Terms Of Surgical Management.

- It Is Defined As An Inguinal Hernia That Extends Below The Midpoint Of Inner Thigh When Patient Is In Standing Position.

\section{CASE REPORT}

- A 50 Year Old Hindu Male, Tea Vendor By Occupation Presented With Complaint Of Inguino-scrotal Swelling For Last 18 Years Gradually Increasing In Size.

- The Patient Had Refused Surgical Treatment For Years, But Now Requested Repair As The Large Size Of The Hernia Was Limiting His Movement And His Ability To Wear Clothing.

- He Did Not Complaint Of Nausea, Vomitting, Gastrointestinal Or Urniary Issues.

- The Patient Was Otherwise In Good Health Adn Did Not Have Any Significant Past Medical Or Surgical History.

- On Inspection Approx. 40*15 Cm Irreducible Inguinoscrotal Swelling Present Extending From Right Inguinal Region Upto The Right Knee With Discolouration Of Overlying Skin Wih Cough Impulse Postive With Single 2*2 Cm Ulcer At The Bottom Of Scrotum .

- On Palpation 40*15 Cm Doughy Swelling With Normal Temperature Non Tender With Thickened Overlying Skin With Positive Cough Pulse, Get Above The Swelling Not Possible.

- Pre-op Usg S/o 8.5 Cm Defect In Right Inguinal Region Through Which Bowel And Mesentry Have Herniated Out.

- Operative repair was approached through a standard transverse inguinal incision.

- The hernia sack was opened and the contents eviscerated.

- The sac contained most of the omentum and few bowel loops.

- The internal ring had to be enlarged in order to reduce the contents into the abdominal cavity. Herniated contents show preserve vascularity. It was difficult to reduce the omentum into the abdominal cavity due to adhesion hence patial omentectomy was done and rest of the bowels were delivered inside the abdominal cavity without resection.
- Monitoring of airway pressures was done to assess the need for compartment enlarging procedures, but was deemed not to be necessary.

- The hernia sac was tied off proximally and the cord structures and testis were spared.

- The previously enlarged internal inguinal ring was closed with interrupted non-absorbable monofilament sutures and the hernia repair was done with a tension-free onlay prosthetic mesh repair.

- The patient did not need any post-operative mechanical ventilatory support.

- On postoperative day 4 seroma formation was noted on right side which was drained.

- Various techniques such as preoperative pneumoperitoneum, debulking abdominal contents with extensive bowel resections, or omentectomy and phrenectomy have been tried. Postoperative elective ventilation is also needed in many cases.

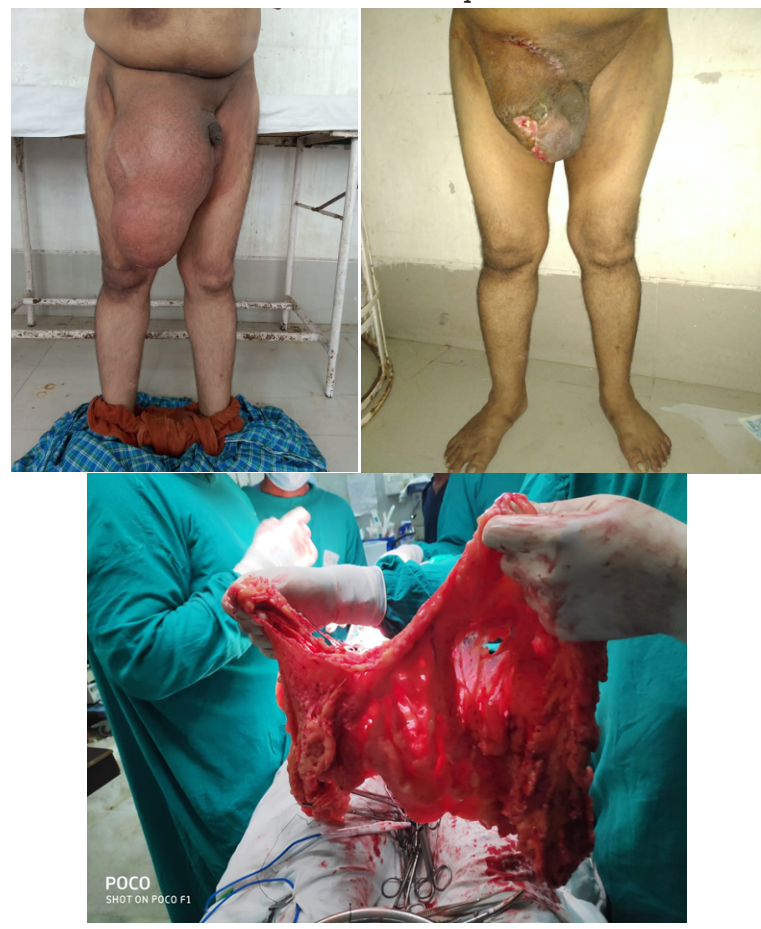

\section{DISCUSSION}

- Giant inguinoscrotal hernias have been defined as those that extend below the midpoint of the inner thigh when the patient is in the standing position.

- The size of the hernia often causes difficulty in walking, 
sitting or lying down. The penis is often buried inside the scrotum causing urine to dribble over the already stretched out scrotal skin. This can lead to ulceration and secondary infection. Patients can also complain of difficulty in voiding.

- Other complications may be incarceration leading to bowel obstruction as well as strangulation of bowel contents.

- Small bowel and omentum is commonly found in the hernia sac though stomach, cecum, appendix, sigmoid colon, urinary bladder and ovaries have been described. A case of herniation of the kidney and ureter has been described.

- In our case, omentum was found as the major content along with bowel.

- There are three specific problems with management of these giant inguinal hernias.

1. Loss of domain.

2. High risk for recurrence.

3. Residual scrotal skin and scrotal haematoma.

\section{REFERENCES}

1. Lau W.Y. History of treatment of groin hernia. World J Surg. 2002;26 (6): 748-759. [PubMed] [Google Scholar]

2. Hodgkinson D.J., Mcllrath D.C. Scrotal reconstruction for giant inguinal hernias. SurgClin North Am. 1980;64:307-313. [PubMed] [Google Scholar]

3. Terezis N.L., Davis W.C., Jackson F.C. Carcinoma of the colon associated with inguinal hernia. N Engl J Med. 1963;268:774-776. [PubMed] [Google Scholar]

4. Maxwell J.W., Davis W.C., Jackson F.C. Colon carcinoma and inguinal hernia. SurgClin North Am. 1965;45(5):1 165-1 171. [PubMed] [Google Scholar]

5. Day T., Ferrara J.J. Preoperative barium contrast enema in patients with inguinal hernia. South Med J. 1986;79(11):1339-1341. [PubMed] [Google Scholar]

6. Leisser A., Delpre G., Kadish U. Colonoscope incarceration: an avoidable event. GastrointestEndosc. 1990;36(6):637-638. [PubMed] [Google Scholar] 